\title{
Purulent Meningitis in Children: A Retrospective Study of 70 Cases in Senegal
}

\author{
Idrissa Basse ${ }^{1}$, Papa Moctar Faye ${ }^{2}$, Amadou Sow ${ }^{3}$,, Marie Acakpo ${ }^{1}$, Ndiogou Seck ${ }^{4}$, Lamine \\ Thiam $^{5}$, Ndieme Ndiaye ${ }^{1}$, Dina Obambi ${ }^{1}$, Djibril Boiro ${ }^{3}$, Aliou Abdoulaye Ndongo ${ }^{6}$, \\ Ndeye Ramatoulaye Diagne Gueye ${ }^{1}$, Ousmane Ndiaye ${ }^{2}$ \\ ${ }^{1}$ Diamniadio Children's Hospital Dakar, University of Thiès, Thies, Senegal \\ ${ }^{2}$ Albert Royer National Children's Hospital, Dakar, Senegal \\ ${ }^{3}$ Abass Ndao Hospital Center, Dakar, Senegal \\ ${ }^{4}$ Regional Hospital of Saint Louis, University of Saint Louis, Saint Louis, Senegal \\ ${ }^{5}$ Regional Hospital of Ziguinchor, University of Ziguinchor, Ziguinchor, Senegal \\ ${ }^{6}$ Aristide Le Dantec Hospital Dakar, Cheikh Anta Diop University of Dakar, Dakar, Senegal
}

Email address:

amadousoow@hotmail.com (A. Sow)

${ }^{*}$ Corresponding author

\section{To cite this article:}

Idrissa Basse, Papa Moctar Faye, Amadou Sow, Marie Acakpo, Ndiogou Seck, Lamine Thiam, Ndieme Ndiaye, Dina Obambi, Djibril Boiro, Aliou Abdoulaye Ndongo, Ndeye Ramatoulaye Diagne Gueye, Ousmane Ndiaye. Purulent Meningitis in Children: A Retrospective Study of 70 Cases in Senegal. International Journal of Infectious Diseases and Therapy. Vol. 5, No. 4, 2020, pp. 127-130.

doi: $10.11648 /$ j.ijidt.20200504.14

Received: October 15, 2020; Accepted: October 27, 2020; Published: November 4, 2020

\begin{abstract}
Introduction: Despite much progress, purulent childhood meningitis (PCM) remains a public health problem. The objective of this work was to determine the epidemiological, clinical, therapeutic and evolutionary profile of purulent meningitis in children. Methods: Based on retrospective work carried out over a 4-year period (01 January 2014 to 31 December 2017), we studied the epidemiological, clinical, therapeutic and evolutionary aspects of cases of purulent meningitis hospitalized in the pediatric ward of the Children's Hospital of Diamniadio. Included were all children from 29 days to 15 years of age in whom the diagnosis of purulent meningitis was confirmed by the laboratory. Results: The hospital frequency was $1.9 \%$. The mean age of the patients was 41.0 months. Among the affected children, $68.6 \%$ were fully vaccinated. The main germ was Neisseria meningitidis W135 (58.8\%). Third generation cephalosporins were the antibiotics of choice (97.1\%). No resistance was found to them. The cure rate with sequelae was 5.7\%. Streptococcus pneumoniae was the germ responsible for $50 \%$ of the objective sequelae. The mortality rate was $7.1 \%$. Conclusion: Neisseria meningitidis W135 is the main germ of purulent meningitis in our study. It is not included in the national routine immunization. It is imperative to adapt vaccination to the epidemiological fluctuation of pathogens in our regions.
\end{abstract}

Keywords: Meningitis, Purulent, Child, Germs, Senegal

\section{Introduction}

Purulent childhood meningitis (PCM) is an endemic disease that remains a topical issue in developing countries, particularly those in the meningitis belt where children are the most vulnerable population [1]. Although much progress has been made, both preventively and curatively, PCM remains a public health problem. Indeed, the bacteriological spectrum of this disease is constantly evolving. Thus, while the preventive measures currently in place have reduced the number of cases of PCM, they have also led to epidemiological fluctuations and the emergence of new germs. Therefore, constant updating of data becomes essential to maintain control over PCM epidemics and to improve curative and preventive management of PCM both at national and sub-regional levels. It is within this framework that we undertook this study whose general 
objective was to determine the epidemiological, clinical, therapeutic and evolutionary profile of PCM.

\section{Methods}

This is a retrospective study conducted over a 4-year period (1 January 2014 to 31 December 2017) at the Diamniadio Children's Hospital (DCH). It is a level III reference pediatric hospital on the health pyramid in Senegal. Included in the study were all hospitalized children aged between 29 days and 15 years whose diagnosis of PCM was confirmed in the laboratory by cerebrospinal fluid (CSF) with a cellularity $>10$ elements $/ \mathrm{mm}^{3}$ with the presence of altered polynuclear cells (APC). All CSF specimens were sent to the laboratory for cytological, chemical and culture studies on non-specific media. The search for soluble antigens in the CSF by latex was done and the antibiogram was systematically performed for any strain isolated in culture. The data were collected from hospitalization records and pediatric ward records and analyzed using Sphinx v5, SPSS 21 and Microsoft Excel 2010 software.

\section{Results}

During the study period, there were 3,526 hospital admissions including 70 confirmed cases of PCM. The hospital frequency was $1.9 \%$. There was a steady increase in PCM cases at DCH between 2014 and 2017 (Figure 1). The disease was present all year round with peaks mainly observed in March and June (Figure 2). The average age of patients was 41 months [extremes of 01 months and 180 months]. The sex ratio was 2.33 . The socio-economic level was low in $57.1 \%$ (40 patients). Of the patients, $68.6 \%$ were fully vaccinated according to the national vaccination programme. The main objective physical signs were fever (62.9\%), stiff neck (46.7\%), Kernig's sign (32\%), Brudzinski's sign (29.2\%) and bulging fontanel (23.3\%). The CSF was cloudy in $45.7 \%$. Bacteria and/or its soluble antigens were detected in $24.3 \%$ of cases. The main germ was Neisseria meningitidis (Nm) W135 (58.8\%). The other germs were Streptococcus pneumoniae (23.5\%), Streptococcus agalactiae (5.9\%), Staphylococcus aureus (5.9\%) and Salmonella spp (5.9\%). No Hib meningitis has been objectified. The different germs objectified according to age are shown in Table 1. Third generation cephalosporins (C3G) were the antibiotics of choice $(97.1 \%)$. No resistance to $\mathrm{C} 3 \mathrm{G}$ was objectified. The cure rate without sequelae was $80 \%$. Sequelae were observed in $5.7 \%$ of cases. Pneumococcus was the germ responsible for $50 \%$ of the cases of objective sequelae. The mortality rate was $7.1 \%$. Figure 3 summarizes the evolution according to the length of hospitalization.

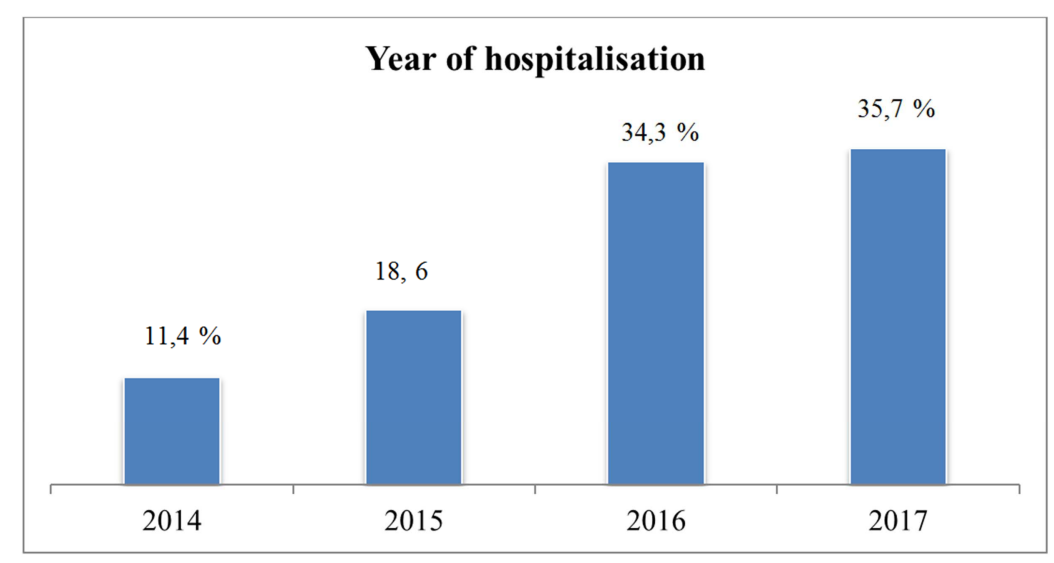

Figure 1. Breakdown by year of hospitalization.

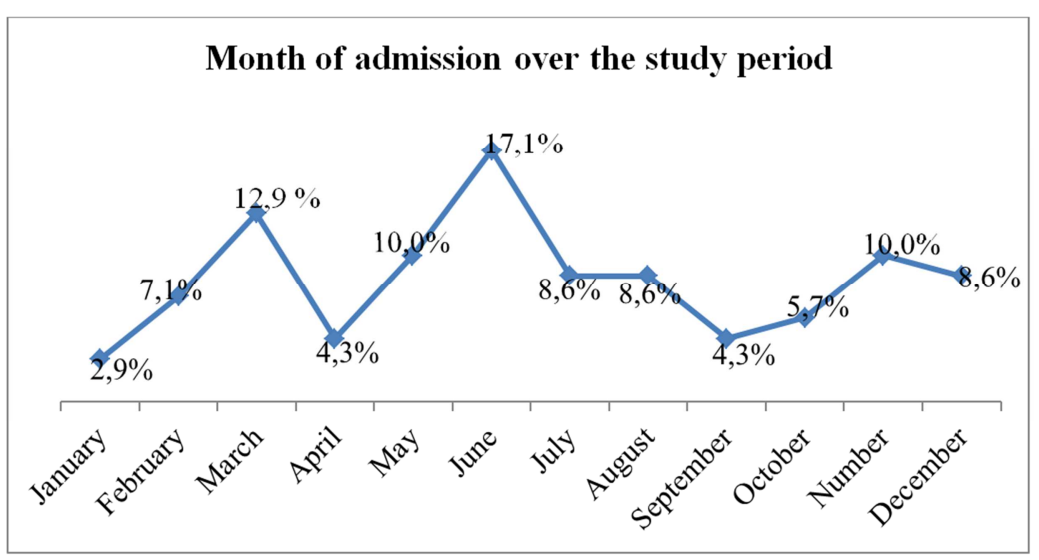

Figure 2. Distribution by month of admission. 


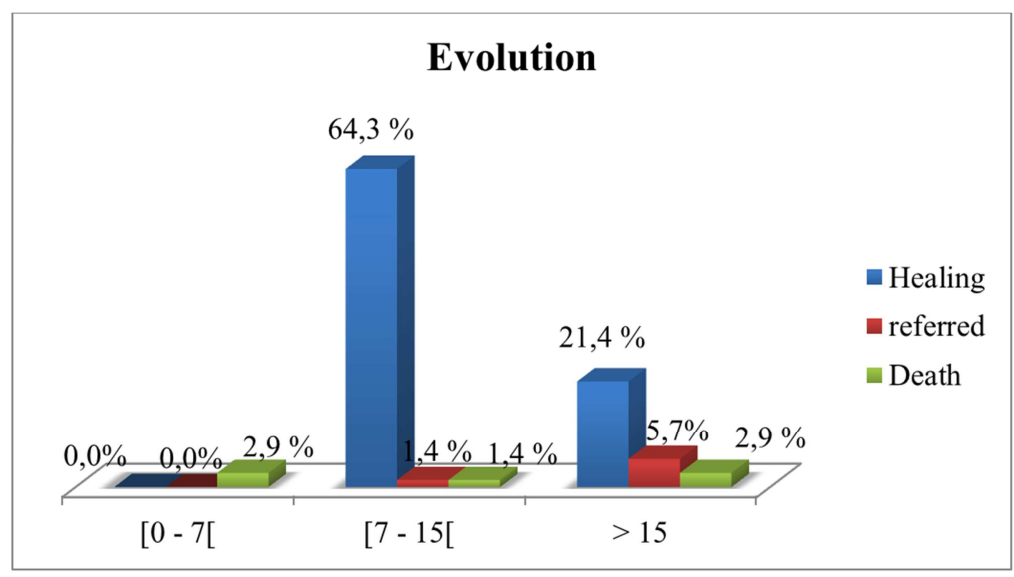

Figure 3. Breakdown according to changes in the length of hospital stay.

Table 1. Distribution according to age and identified germ.

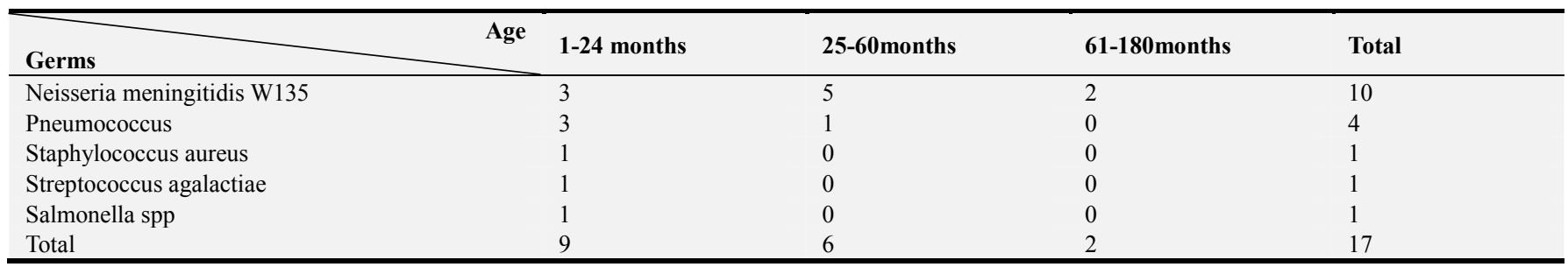

\section{Discussion}

In our study, the hospital frequency of PCM was $1.9 \%$. A study conducted in Senegal in 2003 reported a hospital frequency of $4.9 \%$. [2] This now reflects the regression of PCM. A male predominance was noted (sex ratio $=2.33$ ). This result is in line with other studies carried out in Senegal with a sex ratio of 1.27. [2, 3] However, other studies reported a female predominance. [4, 5] There is therefore no direct relationship between the occurrence of PM and gender. Infants are the most affected age group, as described in the literature. [6-8] PCM mainly affects the lower socio-economic strata of society. The results of our study are consistent with those of the literature. $[2,6,7]$ The predominance of low social strata can be explained by overcrowding, unfavorable lifestyle in this group, as well as lack of vaccination or incomplete vaccination status in some cases. The proportion of children with an up-todate vaccination status was therefore much higher than that of children whose vaccination status was not up to date. This could be due to inefficacy of vaccination for external reasons (conditions of delivery and storage, method of vaccination etc.) or internal to individuals (immunity). Another reason could be a reduction in the effectiveness of vaccination due to a change in the sero-epidemiological profile. [9-11] A bacterium or its soluble antigens were detected in $24.3 \%$ of cases. This result is much lower than those reported in other studies which showed $64 \%$ and $64.8 \%$ respectively. $[7,12]$ This finding shows the inadequacy of our technical support. Among the germs objectified, the main one was $N m W 135$ in $58.8 \%$ of cases. In recent years, many studies have objectified the emergence of Nm. W135 in Senegal. [13-15] Indeed, Nm W135 is now one of the main seeds of objectified PCM in both adults and children. $[9,13,16,17]$ The rate of recovery without sequelae was $80 \%$. This is higher than the rate observed in Senegal in previous studies with $45 \%$ and $67 \%$ respectively. $[18,19]$ One could conclude that with the new curative and preventive treatments, the overall prognosis of PCM has improved considerably in Senegal.

\section{Conclusion}

PCM is a serious condition for which management has improved. Nevertheless, in view of the emergence of new pathogenic agents, it is imperative to adapt vaccination to the epidemiological fluctuation in our regions and therefore to consider integrating new vaccines against PCM into the Senegalese routine immunization programme.

\section{References}

[1] Tikhomirov E, Hallaj Z, 2nd ed. Fighting Meningococcal Meningitis Epidemics WHO Practical Guide. 1998.

[2] Camara B, Cissé MF, Faye PM, Ba M, Tall-Dia A, Diouf S, et al. La méningite purulente en milieu hospitalier pédiatrique à Dakar (Sénégal). Méd Mal infect. 2003; 33: 422-6.

[3] Faye PM, Ba ID, Ba A, Thiongane A, Attiye KM, Sonko A. et al. Pediatric invasive pneumococcal disease in Senegal. Med Mal Infect. 2015; 45 (11-12): 463-9.

[4] Stanislas H. Management of 61 community acute bacterial meningitis cases at the Lille University Hospital from $01 / 01 / 2009$ to $01 / 01 / 2012$ and in line with the 2008 SPILF consensus conference. Medical thesis. Paris:Université du droit et de la sante - Lille 2. 2012. 
[5] Zeggai MEATH. Bacterial meningitis in children. Memory. University Abou Bakr Belkaid Tlemcen; 2014.

[6] Youssouf K. Bacterial meningitis in children aged 0 to 15 years old hospitalised in the paediatrics department of the CHU-Gabriel Toure from January to December 2008. Medical thesis. University of Bamako, 2011.

[7] Souad EH. Purulent meningitis in children: retrospective study of 163 cases at the Hassan II hospital in Agadir (Morocco). Medical thesis. Cheikh Anta DIOP University of Dakar. 2002.

[8] Diop O. Purulent meningitis in children: epidemiology and therapeutic approaches (about 300 cases collected at the H. E. A. R. Thesis of medicine. Cheikh Anta DIOP University of Dakar. 1999.

[9] Osuorah D, Shah B, Manjang A, Secka E, Ekwochi U, Ebenebe J. Outbreak of serotype W135 Neisseria meningitidis in central river region of the Gambia between February and June 2012: a hospital-based review of paediatric cases. Niger J Clin Pract. 2015; 18 (1): 41-7.

[10] Xie O, Pollard AJ, Mueller JE, Norheim G. Emergence of serogroup $\mathrm{X}$ meningococcal disease in Africa: need for a vaccine. Vaccine. 2013; 12, 31 (27): 2852-61.

[11] Delrieu I, Yaro S, Tamekloé TA, Njanpop-Lafourcade BM, Tall H, Jaillard P, et al. Emergence of epidemic Neisseria meningitidis serogroup $\mathrm{X}$ meningitis in Togo and Burkina Faso. PLoS One. 2011; 6 (5): e19513.

[12] Greenhill AR, Phuanukoonnon S, Michael A, Yoannes M, Orami T, Smith H. Streptococcus pneumoniae and Haemophilus influenzae in paediatric meningitis patients at Goroka General Hospital, Papua New Guinea: serotype distribution and antimicrobial susceptibility in the pre-vaccine era. BMC Infect Dis. 2015; 15: 485.
[13] Ba ID, Deme LI, Ba A, Thiongane A, Niang B, Ba A, et al. Meningitis in Neisseria meningitidis W135 of children in Senegal: description of a series of 54 cases collected at the Centre Hospitalier National d'Enfants Albert Royer in Dakar. Dakar Med. 2015; 60 (1).

[14] Manga NM, Ba IO, Diop-Nyafouna SA, Dia-Badiane NM, Fortes-Deguenonvo $\mathrm{L}$, $\mathrm{Ka} \mathrm{D}$, et al. Recurrence of cerebrospinal meningitis and emergence of Neisseria meningitidis W135 in Senegal in 2012. Med Mal Infect. 2013; 43: $13-5$.

[15] Ndour CT, Manga NM, Dia M, Camara B, Cissé F. Meningitis in Neisseria meningitidis W135 in Senegal from 2000- 2009. Med Mal Infect. 2011; 41 (9): 495-7.

[16] Collard JM, Issaka B, Zaneidou M, Hugonnet S, Nicolas P, Taha MK, et al. Epidemiological changes in meningococcal meningitis in Niger from 2008 to 2011 and the impact of vaccination. BMC Infect Dis. 2013; 13: 576.

[17] MenAfriCar consortium. The Diversity of Meningococcal Carriage Across the African Meningitis Belt and the Impact of Vaccination with a Group A Meningococcal Conjugate Vaccine. J Infect Dis. 2015; 212 (8): 1298-307.

[18] Ba O, Fleming JA, Dieye Y, Wa Mutombo BM, Ba M, Cisse MF, et al. Hospital surveillance of childhood bacterial meningitis in Senegal and the introduction of Haemophilus influenzae type $\mathrm{b}$ conjugate vaccine. Am J Trop Med Hyg. 2010; 83 (6): 1330-5

[19] Gomis GCH. Pneumococcal meningitis in paediatric settings: about 362 cases collected at H. E. A. R. Thesis of medicine. Cheikh Anta DIOP University of Dakar. 1998. 